EESTI NSV TEADUSTE AKADEEMIA TOIMETISED. 31. KOIDEE

FOOSIKA * MATEMAATIKA. 1982, NR. 2

ИЗВЕСТИЯ АКАДЕМИИ НАУК ЭСТОНСКОИ ССР. ТОМ 31 ФИЗНКА * МАТЕМАТИКА, 1982, № 2

\title{
ПРОЯВЛЕНИЕ МЕЖМОЛЕКУЛЯРНЫХ ВЗАИМОДЕЙСТВИИ В ТОНКОСТРУКТУРНЫХ СПЕКТРАХ ХЛОРОФИЛЛА И ЕГО АНАЛОГОВ
}

При исследовании спектральных свойств хлорофилла и его аналогов представляется перспективным метод селективной спектроскопии, основанный на устранении неоднородного (при низких температурах) уширения при селективном лазерном возбуждении люминесценции $\left[{ }^{1}\right]$. Әтот метод позволяет получать детальную информацию о колебательном спектре молекул в различных растворителях, моделирующих реальное сольватационное окружение изучаемых молекул.

В настоящей работе рассмотрены примеры применения метода селективной спектроскопии для изучения двух типов межмолекулярных взаимодействий в растворах хлорофилла и его ближайших аналогов, связанных с наиболее активным фотохимическим центром соединений этого класса - с центром порфинового кольца.

Спектральные измерения проводили в неполяризованном свете на установке, описанной в $\left[{ }^{2}\right]$. Важной особенностью установки является система «восстановления» выжженных центров, состоящая из фосфороскопа и мощного источника широкополосного (восстанавливающего) излучения - лампы накаливания.

1. По мнению ряда авторов (см., напр., [ $\left.{ }^{3}\right]$ и ссылки там), в растворе хлорофилла в полярных органических основаниях образуются (в зависимости от силы основания) моносольватированные или дисольватированные формы, представляющие собой координационные соединения с одной или двумя молекулами растворителя, что обусловлено двумя ненасыщенными координационными связями $\mathrm{Mg}$. Можно попытаться выявить спектральные различия сольватированных форм по тонкой вибронной структуре спектров при лазерном возбуждении.

Спектры хлорофилла с разрешенной вибронной структурой ранее были получены и в матрицах Шпольского, и методом селективного возбуждения [ $\left.{ }^{4-6}\right]$. На рис. 1 показаны тонкоструктурные спектры хлорофилла $a$ и его безметального аналога феофитина в эфире при селективном возбуждении в области 0-0-перехода. В этом случае получаются наиболее отчетливые спектры, структура которых соответствует колебаниям молекул в основном электронном состоянии $\left[{ }^{6}\right]$.

Для выявления спектральных признаков сольватационных форм хлорофилла нами был получен также спектр хлорофилла в пиридине и проведено сравнение спектров в разных растворителях. По внешнему виду спектры в пиридине и в эфире мало отличаются друг от друга, однако при анализе колебательной структуры выявляются расхождения в значениях некоторых колебательных частот. В таблице приведены колебательные частоты наиболее интенсивных линий. Некоторые из них (подчеркнутые) в разных растворителях заметно отличаются друг от друга. Детальные измерения показали, что эти расхождения выходят за пределы ошибок. В соответствии с $\left[{ }^{3}\right]$, наблюдаемые различия свя- 


$\begin{array}{lc}\text { В эфире } \\ 348 & 989 \mathrm{~cm}^{-1} \\ 521 & 1149 \\ 573 & \underline{1184} \\ \underline{746} & \underline{1229} \\ \underline{758} & \underline{1327} \\ \underline{915} & \underline{1531}\end{array}$

\section{В пиридинѐ}

$350 \quad 989 \mathrm{CM}^{-1}$

$522 \quad 1149$

$573 \quad 1188$

$\frac{751}{758} \quad \overline{1230}$

$\underline{921} \quad \underline{1531}$
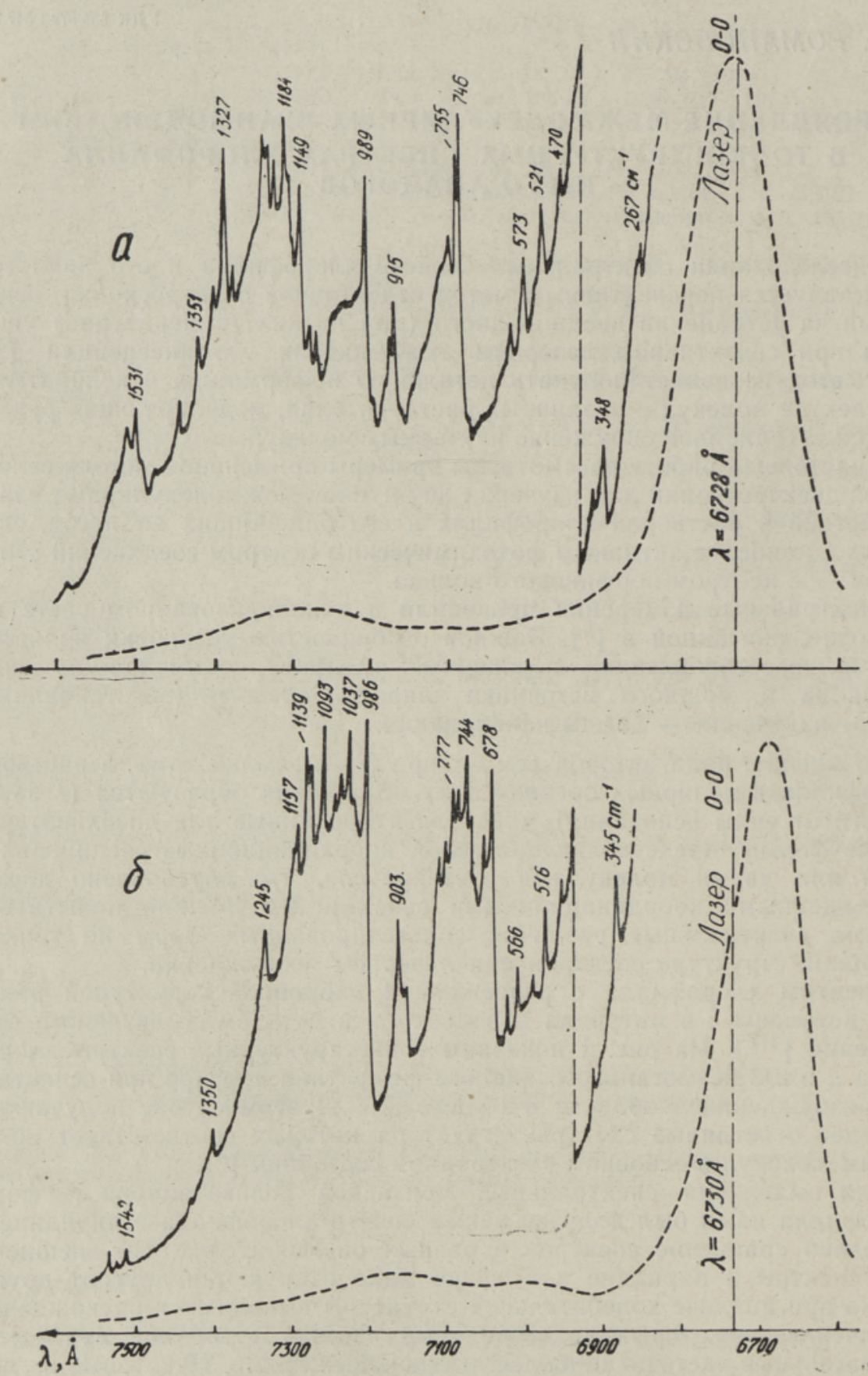

Рис. 1. Спектры флуоресценции хлорофилла $a(a)$ и феофитина (6) в эфире при $T=4,2 \mathrm{~K}:---$ при широкополосном возбуждении в УФ-области, 



Рис. 2. Спектры флуоресценции нейтральной формы копропорфирина-III в смеси эфира с хлороформом (a) и его ионной формы в $\mathrm{H}_{2} \mathrm{O}+10 \%$-ная $\mathrm{HCl}$ (б) при $T=4,2 \mathrm{~K}:-\ldots-$ при широкополосном возбуждении в УФ-области; —— - при лазерном возбуждении.

заны, по-видимому, с изменением степени сольватации в двух разных по силе основаниях (слабом - эфире и сильном - пиридине).

2. Хорошо известна специфическая фотохимическая активность моле- 


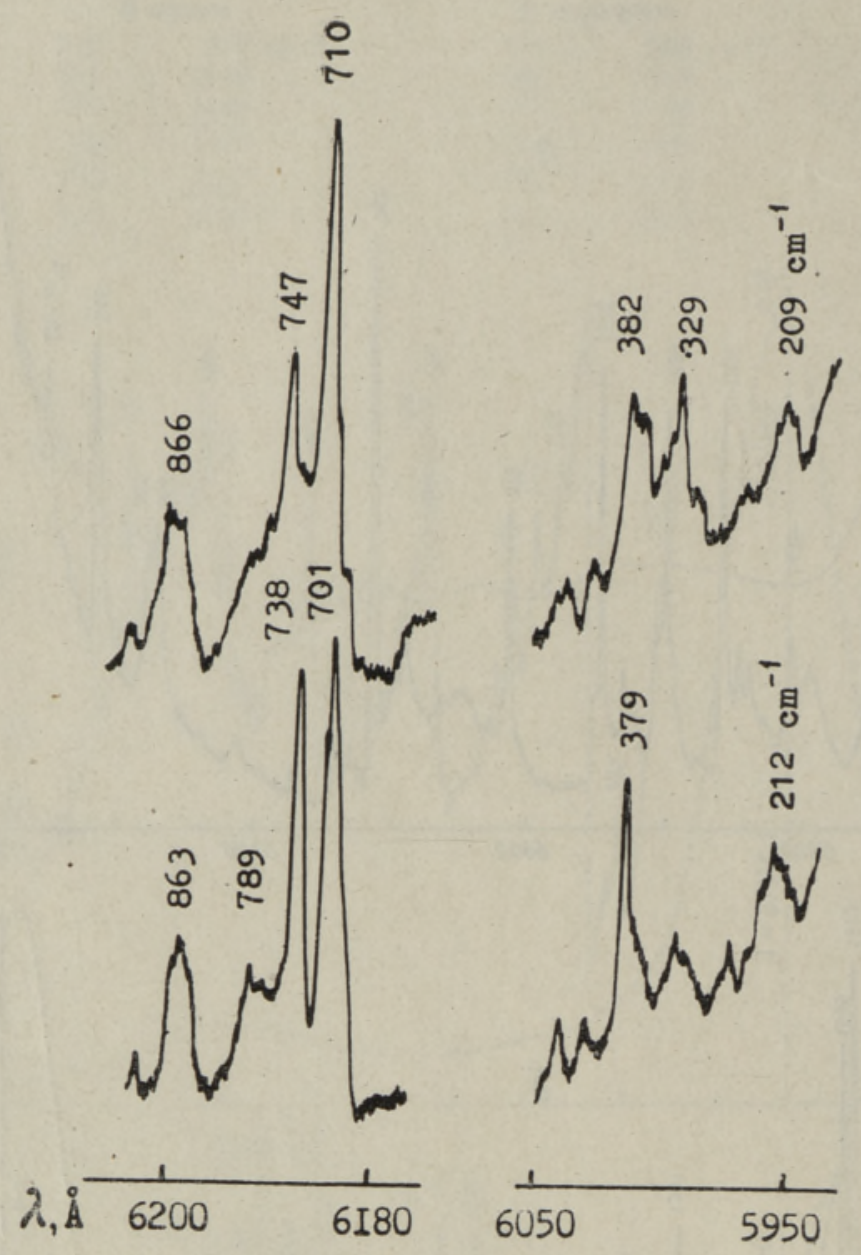

Рис. 3. Фрагменты тонкоструктурных спектров ионной формы копропорфирина-III в $\mathrm{H}_{2} \mathrm{O}+10 \%$-ная $\mathrm{HCl}$ (нижние кривые) и с 10\%-нөй добавкой этанола (верхние кривые), $\lambda_{\text {лаз }}=5880 \AA, T=4,2 \mathrm{~K}$.

кул безметальных порфиринов (среди ближайших аналогов хлорофилла можно отметить феофитин, протофеофитин). Активность таких молекул, как известно, обусловлена возможностью взаимного перемещения двух атомов Н в центре порфинового кольца. При селективном возбуждении это проявляется как характерное «выжигание» примесных молекул $\left[{ }^{7}\right]$.

В кислых растворах молекулы безметальных порфиринов ионизуются, присоединяя свободные протоны раствора к центральным атомам азота иминного типа (см. $\left.{ }^{8}\right]$ и ссылки там). Такая ионизация способна значительно менять фотохимические свойства молекул порфиринов. Например, при двукратной ионизации можно ожидать исчезновения вышеуказанного фотохимического «выжигания». Такое изменение фотохимических свойств молекул при ионизации, несомненно, представляет интерес, поскольку растворы (в частности, водные) с различным рН во многих случаях соответствуют условиям существования порфириновых пигментов в природе.

В данной работе мы рассмотрим эффект ионизации на примере копропорфирина-III в водном растворе $\mathrm{HCl}$, 
На рис. 2 показаны спектры нейтральной (рис. 2,a) и ионной форм копропорфирина-III. Видно, что обычный широкополосный спектр флуоресценции ионов (рис. 2,б, пунктир) значительно смещен в коротковолновую сторону по отношению к спектру нейтральных молекул (рис. 2,a, пунктир) и имеет несколько иное распределение интенсивности. При лазерном возбуждении спектры как нейтральной, так и ионной формы приобретают линейчатую структуру (рис. 2,a,б, сплошные линии). При этом «выжигание», наблюдаемое у нейтральных молекул, в случае ионной формы отсутствует. Это свидетельствует о том, что в ионах центр порфинового кольца имеет более жесткую структуру.

Представляет интерес сопоставить спектры ионной и нейтральной форм. Такое сопоставление показывает, что ширина отдельных вибронных линий, величина фононных крыльев, а также величина неоднородного уширения в спектре ионов мало отличаются от таковых в спектре нейтральных молекул.

Сопоставление вибронной структуры спектров показывает, что в целом они сильно различаются как по частотам колебаний, так и по относительной интенсивности линий. Можно лишь указать на область колебательных частот вблизи $1600 \mathrm{~cm}^{-1}$, где присутствуют наиболее интенсивные линии спектров обеих форм. Эти линии характерны для большинства порфиринов и, как показано в $\left.{ }^{9}\right]$, соответствуют валентным колебаниям атомов углерода пиррольных колец и метиновых мостиков.

В заключение отметим, что мы наблюдали небольшие изменения в тонкоструктурных спектрах иона копропорфирина-III при добавлении в кислый водный раствор этанола (в обычном широкополосном спектре при этом никаких видимых изменений не происходит). Фрагменты тонкоструктурных спектров, иллюстрирующие сказанное, показаны на рис. 3. Такие изменения в вибронной структуре при сохранении общего положения спектра свидетельствуют, по-видимому, о некоторой перестройке структуры периферийных заместителей (слабо связанных с сопряженной $\pi$-электронной системой молекулы). Действительно, как известно $\left[{ }^{10}\right]$, имеющиеся в молекуле копропорфирина карбоксильные группы могут диссошинровать в растворах. причем константа диссошиапии зависит не только от кислотности. но и от приролы растворителя. Возможно, что именно с этим связаны изменения в спектре копропорфирина при добавлении в раствор этанола.

Приведенные выше ланные показывают. что линейчатые спектры при селективном возбуждении могут быть успешно использованы для изучения не только энергетической структvры важных в биологическом отношении порфиринов, но и тонких межмолекулярных взаимодействий в различных средах.

Автор благодарен Л. А. Быковской и Р. И. Персонову за помощь в работе.

\section{Л И Т Е Р А Т У Р А}

1. Персонов Р. И., Альшиц Е. И., Быковская Л. А., Письма в ЖЭТФ, 15, вып. 10, 609-612 (1972).

2. Быковская Л. А., Градюшко А. Т., Персгнов Р. И., Романов . ский Ю. В., Соловьев К. Н., Стапухин А С... Шульга А. М., Ж. прнкладной спектроскопии, 29. вып. 6, 1088-1098 (1978).

3. Cotton. T. M., Trifunac. A. D.. B a $11 \mathrm{schmiter,} \mathrm{K.,} \mathrm{Katz,} \mathrm{J.} \mathrm{J.,} \mathrm{Biochim.}$ Biophys. Acta, 368. $181-198$ (1974).

4. А в а D. м а а Р., Изв. АН ЭССР, Физ. Матем., 23, № 1, 93-94 (1974)

5. Fünfschilling, J., Will i a m s, D. F., Photochem. Photobiol., 26, № 1, 109-113 (1977).

6. Быковская Л. А.. Литвин Ф. Ф., Пепсонов Р. И., Романов с ки й Ю. В., Биофизика, 25, вып. $1,13-20$ (1980).

7. Соловьев К. Н.. Залесский Н. Е.. Котло В. Н., Щкирман С. Ф., Письма в ЖЭТФ, 17, вып. 9, 463-466 (1973). 
8. Гурин ович Г. П., Севченко А. Н., Соловьев К. Н., Спектроскопия хлорофилла и родственных соединений, Минск, «Наука и техника», 1968.

9. Гладков Л. Л., Градюшко А. Т., Соловьев К. Н., Старухин А. С., Ш ульга А. М., Ж. прикладной спектроскопии, 29, вып. 2, 304-309 (1978).

10. N e u ber g e r, A., S c o t t, J. J., Proc. Roy. Soc., A213, 307 (1952).

\section{Институт спектроскопии}

Академии наук СССР

J. V. ROMANOVSKI

\section{MOLEKULIDEVAHELISED VASTASMOJUD KLOROFOLLI} JA TA ANALOOGIDE PEENSTRUKTUURSETES SPEKTRITES

Bioloogiliselt aktiivsete ühendite klorofüll $a$ ja koproporfüriin-III lahuste peenstruktuursetes fluorestsentsispektrites selektiivsel laserergastusel ilmnevate muutuste alusel on kindlaks tehtud kaht tüüpi molekulidevaheline vastasmõju: solvatatsioon ja ionisatsioon.

YU. V. ROMANOVSKIJ

\section{MANIFESTATION OF INTERMOLECULAR INTERACTIONS IN THE FINE-STRUCTURE SPECTRA OF CHLOROPHYLL AND ITS ANALOGUES}

The spectral indications of two types of intermolecular interactions were revealed by the use of the fine-structure spectra under selective laser excitation. These were exemplifield by the important biologically active compounds - chlorophyll $a$ and coproporphyrin-III solutions. 